\title{
Bladder filling volume variation between the first and second days of planning computed tomography for prostate cancer radiation therapy and correlation with renal function
}

Naoya Ishibashi ( $\square$ ishibashi.naoya@nihon-u.ac.jp )

Department of Radiology, Nihon University School of Medicine

Toshiya Maebayashi

Nihon University School of Medicine

Masakuni Sakaguchi

Nihon University School of Medicine

Takuya Aizawa

Nihon University School of Medicine

Masahiro Okada

Nihon University School of Medicine

\section{Research}

Keywords: Bladder filling volume, Planning computed tomography, Prostate cancer, Radiation therapy, Renal function

Posted Date: June 25th, 2020

DOI: https://doi.org/10.21203/rs.3.rs-37803/v1

License: (c) (i) This work is licensed under a Creative Commons Attribution 4.0 International License.

Read Full License 


\section{Abstract}

Background During radiation therapy (RT) for prostate cancer, bladder filling helps exclude the organ from irradiation and reduces adverse effects. For RT planning, we performed computed tomography (CT) for 2 consecutive days to evaluate inter-day variations in organs such as the bladder. However, the patient factors that are associated with large intra-patient variations in bladder filling volume prior to RT are not known. Methods This was a retrospective study of 97 prostate cancer patients who underwent CT for 2 consecutive days for RT planning between March 2015 and March 2020 and with confirmed water intake volume before the scans. Patients consumed $500 \mathrm{~mL}$ of water immediately after urination and underwent CT 30 min after the start of water intake; CT was performed under similar conditions over 2 consecutive days. Patient information was collected from the medical records taken before CT. Results The median bladder filling volume was $102.8 \mathrm{~cm} 3$ (range: 31.7 to 774.0 ) and the median intra-patient bladder filling volume variation was $23.4 \mathrm{~cm} 3$ (range: 0.4 to 277.7 ). Univariate analysis revealed that the intra-patient variation was significantly larger in patients with an eGFR higher than the median ( $P=0.003)$. No other factor showed correlations with the variation. As the larger bladder filling volume of the 2 consecutive days in patients increased (median $121.5 \mathrm{~cm} 3$, range: 47.8 to 774.0 ), the intra-patient variation also increased. Conclusions Patients with a higher eGFR show greater variation in bladder filling volume, and caution should be exercised when applying RT in these patients.

\section{Introduction}

In radiation therapy (RT) for prostate cancer, the bladder, which is adjacent to the prostate, is often filled and excluded from the irradiation field as much as possible to reduce adverse events of the bladder $(1,2$, 3 ). Bladder filling is also useful for excluding the bladder and elevating the small bowel from the irradiation field $(4,5)$. To fill the bladder, water intake is often controlled daily before $R T(3,4,6)$.

Among RT modalities for prostate cancer, intensity-modulated radiation therapy (IMRT) is the most commonly used method and has become increasingly more widespread because it decreases the incidence of adverse events and allows dose escalation $(7,8)$. Before administering IMRT, we performed computed tomography (CT) for RT planning with water intake control for 2 consecutive days to check inter-day variations in various organs including the bladder. In cases in which the location of an organ on the second day of RT planning CT greatly deviates from that on the first day, RT is planned again on the second day.

In the present study, we measured volume variations after bladder filling on the 2 days of planning CT images and investigated the correlations between the variations and patient factors to identify the characteristics of patients with large intra-patient variations.

\section{Patients And Methods}


Of 110 patients with prostate cancer who underwent CT for 2 consecutive days for planning of IMRT between March 2015 and March 2020, 97 patients with confirmed water intake volume before the scans were included in the study. This study was retrospective and informed consent was obtained from all patients. The study was performed in accordance with the Declaration of Helsinki.

\section{Planning CT}

The patients were instructed to drink $500 \mathrm{~mL}$ of water immediately after urination and underwent CT 30 min after the start of water intake. The water intake volume and time to CT were controlled based on the degree of abdominal distension and urgency in the patients. On the second day, CT was performed under the same conditions regarding water intake and scan timing. The patients were immobilized in the supine position with a vacuum-lock cushion (MTVLF15; CIVCO Radiotherapy, lowa, USA), and CT (Aquilion TSX-201A; Toshiba Medical Systems, Tokyo, Japan) was performed during free breathing at $120 \mathrm{kV}$ with automatic exposure control and 2-mm slice thickness. CT images were transferred to a treatment planning system (Monaco version 5; Elekta AB, Stockholm, Sweden). To measure the bladder filling volume, the bladder was contoured by delineating the outer bladder surface. The intra-patient bladder filling volume variation between 2 consecutive days was measured as the difference between the measured volumes. In addition, the same CT images were fused with magnetic resonance images as much as possible, and the prostate was also contoured to measure the prostate volume on planning CT images.

\section{Patient characteristics}

Patient information was collected from the medical records taken before the planning CT. Body mass index (BMI) was calculated from weight and height. The International Prostate Symptom Score (IPSS) (9) was obtained by administering a questionnaire to patients. The estimated glomerular filtration rate (eGFR) was estimated by the following conversion formula for Japanese men: eGFR $\left(\mathrm{mL} / \mathrm{min} / 1.73 \mathrm{~m}^{2}\right)=$ $194 \times$ serum creatinine $(\mathrm{SCr})^{-1.094} \times$ age $^{-0.287}(10)$. For the post-void residual urine volume, the urine volume in the bladder immediately after urination was three-dimensionally measured with an ultrasonic diagnostic apparatus (Bladder Scan BVI 3000 or BVI 6100; Sysmex, Kobe, Japan) (11, 12). Patient age was the age at the time of planning CT.

\section{Statistical analysis}

First, linear regression analysis was performed to evaluate quantitative correlations for intra-patient bladder filling volume variations between 2 consecutive days. Next, regarding the characteristics of patients with a large intra-patient variation, univariate analysis was performed by the Mann-Whitney $U$ test to evaluate age, BMI, IPSS, eGFR, post-void residual urine volume, water intake, and prostate volume on planning CT images. To evaluate whether similar patient factors were correlated with large variations, multivariate analysis was performed by simultaneous logistic regression analysis. In addition, univariate analysis was performed by the Mann-Whitney $U$ test to evaluate whether the intra-patient variations were larger when the larger bladder filling volume of the 2 consecutive days was larger. SPSS version 21.0 (IBM, Armonk NY, USA) was used for statistical analysis. 


\section{Results}

The characteristics of the 97 patients included in this study are summarized in Table 1. The median age was 76 years (range: 63 to 88 ). The median eGFR was $61.6 \mathrm{~mL} / \mathrm{min} / 1.73 \mathrm{~m}^{2}$ (range: 4.4 to 98.8 ). There were no patients on dialysis. The largest water intake volume was $500 \mathrm{~mL}$ in 73 patients, followed by $400 \mathrm{~mL}$ in 12 patients. The median bladder filling volume on all CT images in all patients was $102.8 \mathrm{~cm}^{3}$ (range: 31.7 to 774.0). The median of the larger bladder filling volume of the 2 consecutive days in patients was $121.5 \mathrm{~cm}^{3}$ (range: 47.8 to 774.0 ). The median intra-patient bladder filling volume variation was $23.4 \mathrm{~cm}^{3}$ (range: 0.4 to 277.7 ). 
Table 1

Characteristics of patients with prostate cancer $(n=97)$

\section{Characteristics}

Age (years) at planning CT

Body mass index

IPSS

eGFR $\left(\mathrm{mL} / \mathrm{min} / 1.73 \mathrm{~m}^{2}\right)$

Post void residual urine volume $(\mathrm{mL})$

T stage (no.)

T1c

$\mathrm{T} 2 \mathrm{a}$

$\mathrm{T} 2 \mathrm{~b}$

$\mathrm{T} 2 \mathrm{C}$

T3a

$\mathrm{T} 3 \mathrm{~b}$

Water intake $(\mathrm{mL})$ (no.) before planning CT

200

300

350

400

500

800

Prostate volume at planning CT $\left(\mathrm{cm}^{3}\right)$

Bladder filling volume $\left(\mathrm{cm}^{3}\right)$ at all planning CT inter patients

Larger bladder filling volume $\left(\mathrm{cm}^{3}\right)$ between 1 st and 2 nd day intra patient

Bladder filling volume variation $\left(\mathrm{cm}^{3}\right)$ between 1 st and 2 nd day intra patient
Median (range)

$76(63-88)$

$23.87(17.69-34.66)$

$7(0-31)$

$61.6(4.4-98.8)$

$21(0-493)$

33

26

6

9

15

8

1

8

2

12

73

1

$25.0(8.2-56.8)$

$102.8(31.7-774.0)$

$121.5(47.8-774.0)$

$23.4(0.4-277.7)$ 
Linear regression analysis revealed a very large variation in data on intra-patient variations $\left(R^{2}=0.55\right)$ (Fig. 1). The median intra-patient variation was $16.9 \mathrm{~cm}^{3}$ in patients with an eGFR< $61.6 \mathrm{~mL} / \mathrm{min} / 1.73 \mathrm{~m}^{2}$ (median) and $33.5 \mathrm{~cm}^{3}$ in patients with an eGFR $\geq 61.6 \mathrm{~mL} / \mathrm{min} / 1.73 \mathrm{~m}^{2}$. Univariate analysis revealed that the intra-patient variation was much larger in patients with a higher eGFR ( $P=0.003$; Table 2$)$. Multivariate analysis also revealed that a higher eGFR was correlated with a larger intra-patient variation ( $P=0.042$; Table 3$)$. No correlation was observed between other patient factors and the variation. 
Table 2

Results of univariate analyses of associations between patient characteristics and bladder filling volume variation between $1 \mathrm{st}$ and 2 nd day intra-patient

\begin{tabular}{|c|c|c|}
\hline Patient characteristics & $\begin{array}{l}\text { Bladder filling volume variation }\left(\mathrm{cm}^{3}\right) \text {, median } \\
\text { (range) }\end{array}$ & $\begin{array}{l}P \\
\text { value }\end{array}$ \\
\hline \multicolumn{3}{|c|}{ Age (years) at planning CT } \\
\hline$<76$ & $28.1(0.4-277.7)$ & 0.334 \\
\hline$\geq 76$ & $20.8(0.6-208.3)$ & \\
\hline \multicolumn{3}{|l|}{ Body mass index } \\
\hline$<23.87$ & $28.9(2.1-277.7)$ & 0.135 \\
\hline$\geq 23.87$ & $20.2(0.4-161.9)$ & \\
\hline \multicolumn{3}{|l|}{ IPSS } \\
\hline$<7$ & $31.6(1.0-208.3)$ & 0.333 \\
\hline$\geq 7$ & $20.6(0.4-277.7)$ & \\
\hline \multicolumn{3}{|l|}{$\operatorname{eGFR}\left(\mathrm{mL} / \mathrm{min} / 1.73 \mathrm{~m}^{2}\right)$} \\
\hline$<61.6$ & $16.9(0.4-133.3)$ & $0.003^{*}$ \\
\hline$\geq 61.6$ & $33.5(0.6-277.7)$ & \\
\hline \multicolumn{3}{|c|}{$\begin{array}{l}\text { Post void residual urine volume } \\
(\mathrm{mL})\end{array}$} \\
\hline$<21$ & $20.4(0.4-277.7)$ & 0.379 \\
\hline$\geq 21$ & $31.0(0.6-208.3)$ & \\
\hline \multicolumn{3}{|l|}{ Water intake $(\mathrm{mL})$} \\
\hline$<500$ & $25.7(2.5-277.7)$ & 1.000 \\
\hline$\geq 500$ & $22.2(0.4-208.3)$ & \\
\hline \multicolumn{3}{|c|}{$\begin{array}{l}\text { Prostate volume at planning CT } \\
\left(\mathrm{cm}^{3}\right)\end{array}$} \\
\hline$<25.0$ & $20.2(0.6-277.7)$ & 0.834 \\
\hline$\geq 25.0$ & $29.0(0.4-161.9)$ & \\
\hline
\end{tabular}


Table 3

Multivariate analyses of predictors of bladder filling large volume variation between 1 st and 2 nd day intra-patient

\begin{tabular}{|llll|}
\hline Prognostic factors & OR & $95 \% \mathrm{Cl}$ & P-value \\
\hline Age at planning CT (years) & & & \\
\hline$<76$ vs. $\geq 76$ & 0.638 & $0.253-1.609$ & 0.341 \\
\hline Body mass index & & & \\
\hline$<23.86$ vs. $\geq 23.86$ & 0.474 & $0.184-1.218$ & 0.121 \\
\hline IPSS & & & \\
\hline$<7$ vs. $\geq 7$ & 0.469 & $0.187-1.177$ & 0.107 \\
\hline eGFR (mL/min/1.73 $\left.\mathrm{m}^{2}\right)$ & & & \\
\hline$<61.9$ vs. $\geq 61.9$ & 2.529 & $1.032-6.197$ & $0.042 \star$ \\
\hline Post void residual urine volume $(\mathrm{mL})$ & & & \\
\hline$<24$ vs. $\geq 24$ & 2.351 & $0.928-5.955$ & 0.071 \\
\hline Water intake $(\mathrm{mL})$ & & & \\
\hline$<500$ vs. $\geq 500$ & 0.748 & $0.272-2.059$ & 0.574 \\
\hline Prostate volume at planning CT $\left(\mathrm{cm}^{3}\right)$ & & & \\
\hline$<25.0$ vs. $\geq 25.0$ & 1.505 & $0.626-3.615$ & 0.361 \\
\hline
\end{tabular}

In addition, as the larger volume of the bladder filling volume between 2 days of CT in patients increased, the intra-patient variation also increased. This volume and the intra-patient variation were strongly correlated $(P<0.01$; Fig. 2).

\section{Discussion}

The bladder filling volume greatly varies during RT for prostate cancer $(6,13,14)$. Some studies also reported that the bladder filling volume decreases during $\mathrm{RT}(4,14)$. This variation is also correlated with the motion of the target prostate $(13,14)$. For this reason, it is important to keep the bladder filling volume as constant as possible, and patients are often instructed to control urination and water intake to ensure bladder filling before $\mathrm{CT}$. For planning $\mathrm{CT}$, our patients are required to drink $500 \mathrm{~mL}$ of water immediately after urination and $\mathrm{CT}$ is performed $30 \mathrm{~min}$ after the start of water intake.

Previous studies have only compared bladder volume on CT images before and during RT. The interpatient variation ranged from 70 to $509 \mathrm{~cm}^{3}$ (13); the average volume ranged from 94 to $317 \mathrm{~cm}^{3}$ (4), and the intra-patient variation showed a mean decrease of $124 \mathrm{~cm}^{3}$ after treatment (14). To the best of our 
knowledge, the present study is the first to confirm that the intra- and inter-patient bladder filling volume variations were extremely large even during 2 consecutive days of controlling urination and water intake in patients with the bladder unaffected by RT. One study reported that the bladder volume measured on CT images ranged from 41.0 to $1501.3 \mathrm{~cm}^{3}$ in 419 patients without bladder disease in whom neither urination nor water intake was controlled (15). Although a large inter-patient variation was observed, no association between the volume and patient factors was investigated. The present study is the first to examine the correlation between the bladder filling volume variation and patient factors. Our results revealed that the variation was much larger in patients with a higher eGFR, or with better renal function.

Regarding renal function, $\mathrm{SCr}$ levels are dependent on the muscle mass and dietary intake required for creatinine generation (16). GFR is the most accurate index to evaluate overall renal function and is estimated based on age, sex, and race, among other factors. GFR more accurately reflects the renal function than SCr levels alone and is widely used $(17,18)$. In the present study, we used the conversion formula developed from SCr levels and other data in 763 Japanese patients (10). Some previous reports indicated that the bladder filling volume greatly varied during RT in patients with the larger bladder filling volume at the time of planning CT $(4,6,19,20)$. For example, in one study, there was a significantly larger bladder filling volume variation during RT in the $1080 \mathrm{~mL}$ water intake arm compared with the $540 \mathrm{~mL}$ arm (19). In cases in which the bladder filling volume at the time of planning CT was larger, the mean relative bladder volume (bladder volume on treatment cone beam $\mathrm{CT}[\mathrm{mL}] /$ bladder volume on planning CT $[\mathrm{mL}] \times 100 \%$ ) was smaller (20). In the present study, we observed larger intra-patient variation in patients in which the larger bladder filling volume of the 2 consecutive days was larger. This result was comparable with the results of the previous reports.

Our results show that the bladder filling volume greatly varies in patients with a higher eGFR. When RT is planned in such patients, caution should be exercised. When RT planning CT was performed in cervical cancer patients with an empty bladder after urination, bladder volume variations were small, and exposure doses to the small bowel were within the acceptable range (21). For patients with a higher eGFR, the performance of RT planning CT with an empty bladder may also be considered. In the future, we will conduct additional investigations to evaluate variations in the bladder volume measured by RT planning CT with an empty bladder.

\section{Abbreviations}

$\mathrm{RT}$, radiation therapy; IMRT, intensity-modulated radiation therapy; CT, computed tomography; BMI, body mass index; IPSS, International Prostate Symptom Score; eGFR, estimated glomerular filtration rate

\section{Declarations}

\section{Ethics approval and consent to participate}

Not applicable. 


\section{Consent for publication}

The patients were fully informed and provided consent for publication of this study. This retrospective study was approved by the institutional review board of Nihon University School of Medicine.

\section{Availability of data and material}

The data used during this study are available from the corresponding author on reasonable request.

\section{Competing interests}

Drs. Ishibashi, Maebayashi, Sakaguchi, Aizawa and Okada declare that they have no competing interests.

\section{Funding}

None.

\section{Authors' contributions}

$\mathrm{NI}$ treated the patient and was a major contributor to writing the manuscript. TM, MS, TA and MO took part in the treatment. All authors read and approved the final manuscript.

Acknowledgments: We thank Gabrielle White Wolf, PhD, from Edanz Group (https://en-authorservices.edanzgroup.com/) for editing a draft of this manuscript.

\section{References}

1. Rex Cheung M, Tucker SL, Dong L, et al. Investigation of Bladder Dose and Volume Factors Influencing Late Urinary Toxicity After External Beam Radiotherapy for Prostate Cancer. Int J Radiat Oncol Biol Phys. 2007;67(4):1059-65. doi:10.1016/j.ijrobp.2006.10.042.

2. Dearnaley DP, Hall E, Lawrence D, et al. Phase III Pilot Study of Dose Escalation Using Conformal Radiotherapy in Prostate Cancer: PSA Control and Side Effects. Br J Cancer. 2005;92(3):488-98. doi:10.1038/sj.bjc.6602301.

3. Rosewall T, Catton C, Currie G, et al. The Relationship Between External Beam Radiotherapy Dose and Chronic Urinary Dysfunction-A Methodological Critique Radiother Oncol. 2010; 97(1): 40-47. doi: 10.1016/j.radonc.2010.08.002.

4. Lebesque JV, Bruce AM, Kroes AP, Touw A, Shouman RT, van Herk M. Variation in Volumes, DoseVolume Histograms, and Estimated Normal Tissue Complication Probabilities of Rectum and Bladder During Conformal Radiotherapy of T3 Prostate Cancer. Int J Radiat Oncol Biol Phys. 1995;33(5):1109-19. doi:10.1016/0360-3016(95)00253-7.

5. Nuyttens JJ, Robertson JM, Yan D, Martinez A. The Position and Volume of the Small Bowel During Adjuvant Radiation Therapy for Rectal Cancer. Int J Radiat Oncol Biol Phys. 2001;51(5):1271-80. doi:10.1016/s0360-3016(01)01804-1. 
6. Tara Rosewall J, Wheat G, Currie, et al. Planned Versus 'Delivered' Bladder Dose Reconstructed Using Solid and Hollow Organ Models During Prostate Cancer IMRT. Radiother Oncol. 2016;119(3):417-22. doi:10.1016/j.radonc.2016.03.022.

7. Bruce L, Jacobs Y, Zhang, Florian R, Schroeck, et al. Use of Advanced Treatment Technologies Among Men at Low Risk of Dying From Prostate Cancer. JAMA. 2013;309(24):2587-95. doi:10.1001/jama.2013.6882.

8. Bruce $L$, Jacobs $Y$, Zhang, Ted A, Skolarus, et al. Comparative Effectiveness of External-Beam Radiation Approaches for Prostate Cancer. Eur Urol. 2014;65(1):162-8. doi:10.1016/j.eururo.2012.06.055.

9. Bosch JL, Hop WC, Kirkels WJ, Schröder FH. The International Prostate Symptom Score in a Community-Based Sample of Men Between 55 and 74 Years of Age: Prevalence and Correlation of Symptoms With Age, Prostate Volume, Flow Rate and Residual Urine Volume. Br J Urol. 1995;75(5):622-30. doi:10.1111/j.1464-410x.1995.tb07421.x.

10. Seiichi Matsuo E, Imai M, Horio, et al. Collaborators developing the Japanese equation for estimated GFR. Revised Equations for Estimated GFR From Serum Creatinine in Japan. Am J Kidney Dis. 2009;53(6):982-92. doi:10.1053/j.ajkd.2008.12.034.

11. Ung KA, White R, Mathlum M, Mak-Hau V, Lynch R. Comparison Study of Portable Bladder Scanner Versus Cone-Beam CT Scan for Measuring Bladder Volumes in Post-Prostatectomy Patients Undergoing Radiotherapy. J Med Imaging Radiat Oncol. 2014;58(3):377-83. doi:10.1111/17549485.12171.

12. Laura Mullaney, Evelyn O'Shea MT, Dunne PG, Thirion, John G, Armstrong. A Comparison of Bladder Volumes Based on Treatment Planning CT and BladderScan ${ }^{\circledR}$ BVI 6100 Ultrasound Device in a Prostate Radiation Therapy Population. Br J Radiol. 2018;91(1091):20180160. doi:10.1259/bjr.20180160.

13. Roeske JC, Forman JD, Mesina CF, et al. Evaluation of Changes in the Size and Location of the Prostate, Seminal Vesicles, Bladder, and Rectum During a Course of External Beam Radiation Therapy. Int J Radiat Oncol Biol Phys. 1995;33(5):1321-9. doi:10.1016/0360-3016(95)00225-1.

14. Zellars RC, Roberson PL, Strawderman M, et al. Prostate Position Late in the Course of External Beam Therapy: Patterns and Predictors. Int J Radiat Oncol Biol Phys. 2000;47(3):655-60. doi:10.1016/s0360-3016(00)00469-7.

15. Ghaneh Fananapazir A, Kitich R, Lamba SL, Stewart MT, Corwin. Normal Reference Values for Bladder Wall Thickness on CT in a Healthy Population. Abdom Radiol (NY). 2018;43(9):2442-5. doi:10.1007/s00261-018-1463-x.

16. Gary L, Myers WG, Miller J, Coresh, et al National Kidney Disease Education Program Laboratory Working Group. Recommendations for Improving Serum Creatinine Measurement: A Report From the Laboratory Working Group of the National Kidney Disease Education Program. Clin Chem. 2006;52(1):5-18. doi:10.1373/clinchem.2005.0525144. 
17. Lesley A, Stevens J, Coresh T, Greene, Andrew S, Levey. Assessing Kidney Function-Measured and Estimated Glomerular Filtration Rate. N Engl J Med. 2006;8(23):2473-83. doi:10.1056/NEJMra054415. 354 ) .

18. Lothar Thomas, Andreas R, Huber. Renal Function-Estimation of Glomerular Filtration Rate. Clin Chem Lab Med. 2006;44(11):1295-302. doi:10.1515/CCLM.2006.239.

19. Mullaney LM, O'Shea E, Dunne MT, et al. A randomized trial comparing bladder volume consistency during fractionated prostate radiation therapy. Pract Radiat Oncol. 2014;4(5):e203-12. doi:10.1016/j.prro.2013.11.006.

20. Fujioka C, Ishii K, Yamanaga T, et al. Optimal bladder volume at treatment planning for prostate cancer patients receiving volumetric modulated arc therapy. Pract Radiat Oncol. 2016;6(6):395-401. doi:10.1016/j.prro.2016.05.007.

21. Victor E, Chen EF, Gillespie, Ryan P, Manger, et al. The Impact of Daily Bladder Filling on Small Bowel Dose for Intensity Modulated Radiation Therapy for Cervical Cancer. Med Dosim. 2019;44(2):102-6. doi:10.1016/j.meddos.2018.02.010.

\section{Figures}




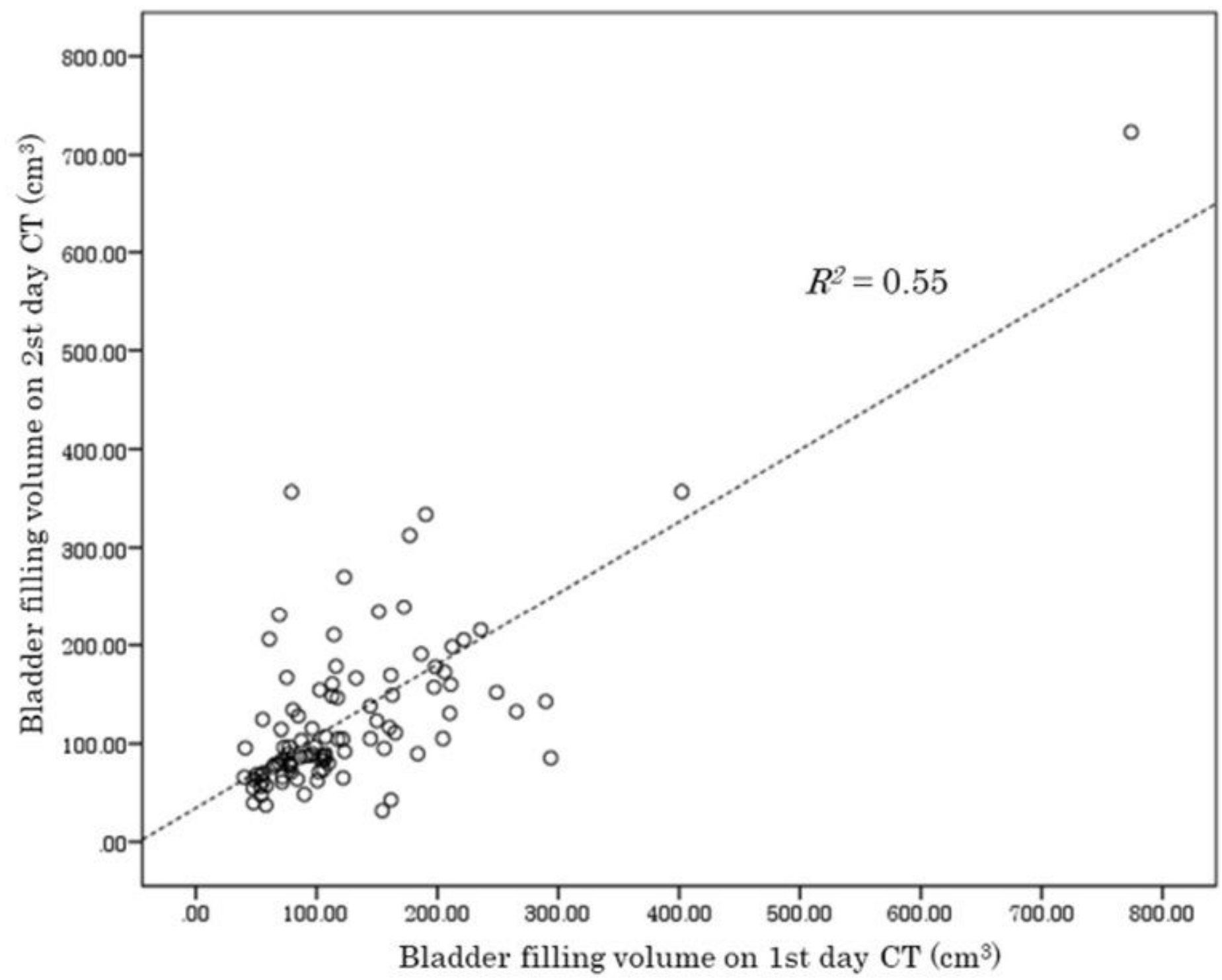

Figure 1

Linear regression analysis of bladder filling volume variation between 1 st and 2 nd day CT. Linear regression analysis revealed very large intra-patient variations $(R 2=0.55)$. 


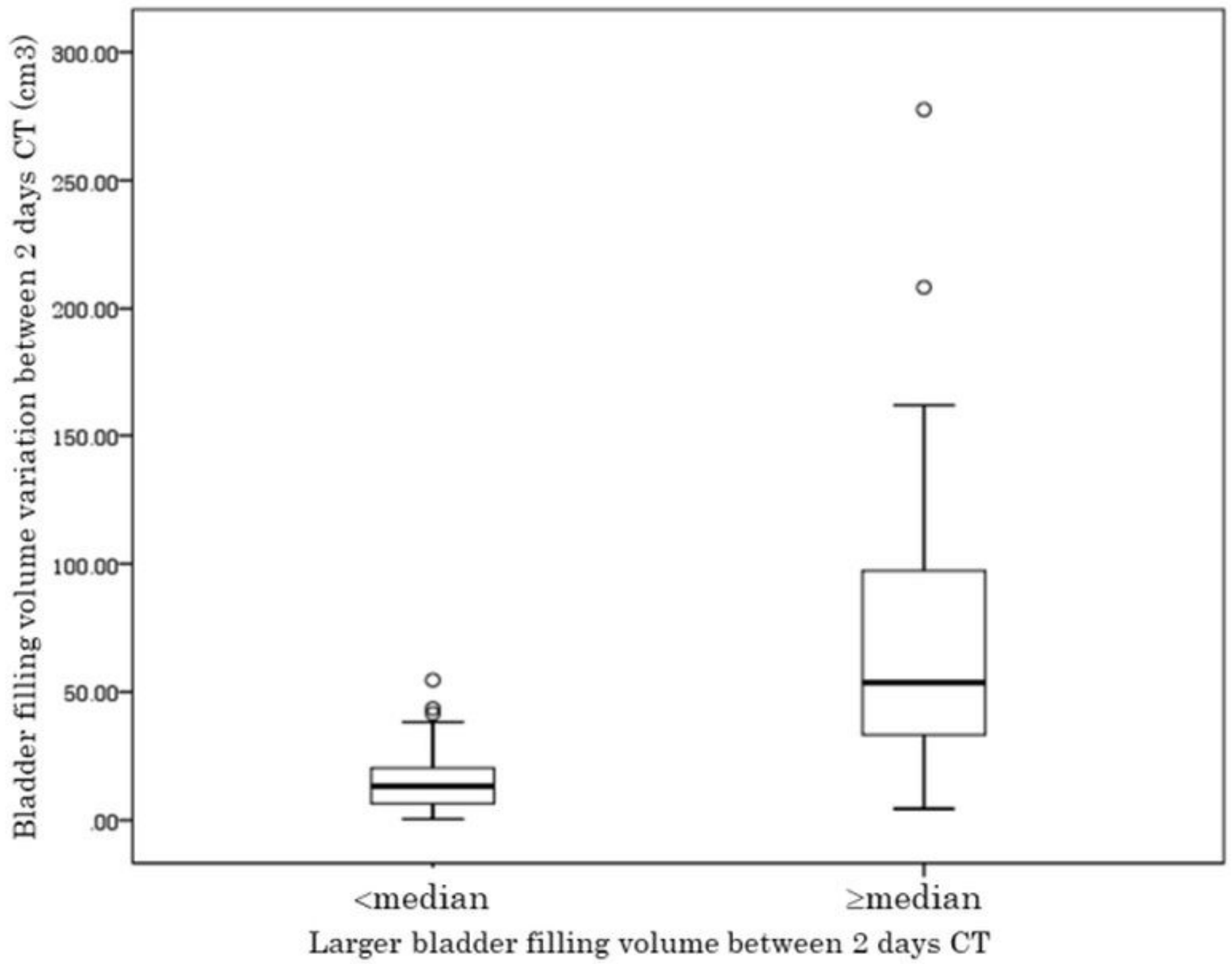

Figure 2

Box and whisker plot of bladder filling volume variation between 1st and 2nd day CT. X-axis shows larger bladder filling volume intra-patient (<median vs. >=median). This volume and the intra-patient variation were strongly correlated $(P<0.01)$. 